\title{
Willingness to Pay Price Premium for Smartphones Produced Using Renewable Energy
}

\author{
Ju-Hee Kim, Hyo-Jin Kim and Seung-Hoon Yoo * \\ Department of Energy Policy, Graduate School of Energy \& Environment, Seoul National University \\ of Science \& Technology, 232 Gongreung-Ro, Nowon-Gu, Seoul 01811, Korea; \\ jhkim0508@seoultech.ac.kr (J.-H.K.); hjinkim@seoultech.ac.kr (H.-J.K.) \\ * Correspondence: shyoo@seoultech.ac.kr; Tel.: +82-2-970-6802
}

Received: 2 February 2019; Accepted: 11 March 2019; Published: 14 March 2019

\begin{abstract}
Due to air pollution and greenhouse gases issues associated with the use of fossil fuels and nuclear safety issues after the Fukushima accident, consumers are increasingly in favor of commodities produced using electricity generated from relatively expensive renewable energy (RE) rather than cheap fossil fuels or nuclear energy. This is usually called 'RE100'. The objective of this study is to examine South Korean consumers' willingness to pay (WTP) price premium for a RE100 commodity using the specific case of smartphones. We accomplished the purpose by conducting a contingent valuation survey of 1000 individuals in August 2018 and analyzing the data gathered from the survey. In addition, the spike model was applied to dealing with the zero WTP responses. Based on the analysis results, an average price premium was statistically significantly estimated to be KRW 11,699 (USD 10.5) for all respondents. This is worth $1.6 \%$ of the price for a conventional non-RE100 smartphone (KRW 750,000 or USD 673.9) and is higher than the cost increase $(0.97 \%)$ when producing RE100 smartphones. Therefore, it can be seen that South Korean consumers have sufficient acceptance for RE100 smartphones.
\end{abstract}

Keywords: renewable energy; contingent valuation; consumer preference; smartphone; price premium

\section{Introduction}

The rapid increase in greenhouse gas (GHG) emitted from fossil fuels has strengthened global warming and has recently caused abnormal weather conditions worldwide. In addition, nuclear energy is not expected to increase due to the safety concerns generated, particularly after the Fukushima nuclear disaster. As a result, renewable energy (RE) consumption has become a topic and increased in several high-income countries [1]. In order to support the increase in RE consumption, power market restructuring policies have been implemented in some regions and countries, including Europe and the US. Previously, power consumers were unable to select primary energy, the raw material used to produce electricity, but after restructuring the power market, a number of suppliers entered the power market, expanding and facilitating consumers' purchase of RE.

In this situation, the Climate Group, a multinational non-profit organization working to address climate change issues, first introduced the 'RE 100\%' (RE100) campaign at the Climate Week held in New York City in 2014. Because of the RE100 initiative, which aims to produce electricity from $100 \%$ $\mathrm{RE}$, companies are more willing to consume electricity generated from RE sources. Since the launch of RE100 in 2014, 157 companies from around the world have joined as of December 2018. In addition, as companies that had joined RE100 have asked their subcontractors to participate in the use of RE, the RE100 is expected to proliferate. As the number of companies joining RE100 continues to increase, 
products produced using $100 \%$ RE are expected to increase as well, and in this study, such products are described as 'RE100 commodity'.

In response to this global change, Samsung Electronics, South Korea's largest electronics producer, pledged RE100 by 2020 in 2018 [2]. RE100 commodities contribute to reducing GHG emissions compared to non-RE100 commodities. However, the cost of producing RE100 commodities is higher than that of producing non-RE100 commodities. Therefore, it is natural that the price of a RE100 commodity is higher than that of a non-RE100 commodity. Because the objective that a company seeks is to increase consumer satisfaction, identifying consumers' preference and willingness to pay (WTP) before investing should precede. We can evaluate consumers' acceptance of RE100 commodities by obtaining additional WTP or price premiums for RE100 commodities over non-RE100 commodities. Concretely, this study adopted smartphones as a RE100 commodity, which is a common electronic device in South Korea.

More specifically, this paper aimed to analyze consumers' WTP price premium for a RE100 smartphone in South Korea. For this purpose, 1000 South Korean consumers were surveyed, applying the contingent valuation (CV) method, in August 2018. CV is a widely-used survey method for estimating WTP, which involves constructing a hypothetical market in a survey. In this study, it was assumed that all other conditions are the same, considering whether the commodity is produced using $100 \%$ RE. Specifically, to make it easier for respondents to understand, Samsung Electronics' most popular latest model, Galaxy S9, has become the standard. That is, it was assumed that the existing Galaxy S9, which is a non-RE100 commodity since Samsung Electronics has not yet used RE, was to become a RE100 commodity by Samsung Electronics' participating in RE100.

Arrow et al. [3] provided several recommendations and explained that reliable estimates can be gained through the CV method if several conditions are met and the results can be the basis of decision making. Furthermore, they emphasized respondents' familiarity with the good to be evaluated and professional interviewing skills for the purpose of obtaining more precise results [4-7]. This study was carefully designed under these conditions. The remainder of this article comprises three components. The methodology adopted in this paper is reported in Section 2. The penultimate section deals with the data, the empirical results, and discussions. The final section contains the conclusions.

\section{Methodology}

\subsection{Literature Review}

Recently, as environmental concerns have grown, interest in eco-friendly products has increased. Especially for electronic products, eco-friendly products are divided into two main types. One is that the manufacturing process of a product is environmentally friendly, and the other is to reduce environmental damage in use, such as increasing the energy efficiency of the product. In this study, we studied products corresponding to the former, and the advance study cases are summarized in Table 1. There have been studies on consumers' preferences and WTP for environmentally friendly products rather than conventional ones, which mainly have applied the stated preference method. There are two main approaches, $\mathrm{CV}$ and choice experiment (CE). 
Table 1. Summary of advance studies.

\begin{tabular}{cccl}
\hline Countries & \multicolumn{1}{c}{ Sources } & Methodologies a & \multicolumn{1}{c}{ Main Results } \\
\hline United States & Saphores et al. [8] & CE & $\begin{array}{l}\text { Most consumers in California are willing to pay only a 1\% } \\
\text { premium for 'greener' consumer electronic devices. }\end{array}$ \\
\hline United States & Ward et al. [9] & CE & $\begin{array}{l}\text { U.S. consumers' mean additional willingness to pay (WTP) for } \\
\text { a refrigerator manufactured by a company that is a member of } \\
\text { Green Power Partnership is USD 48.52 to USD 70.95. }\end{array}$ \\
\hline United States & Milovantseva [10] & CV & $\begin{array}{l}\text { According to WTP estimates, people are willing to pay an } \\
\text { average of USD 5.63 to USD 29.55 to purchase a green cell } \\
\text { phone over a conventional one with same functionalities. }\end{array}$ \\
\hline South Korea & Min et al. [11] & CV & $\begin{array}{l}\text { The mean additional WTP a premium for eco-labeled 43-inch } \\
\text { LED TV is estimated to be KRW 29007 (USD 24.8). }\end{array}$ \\
\hline \multicolumn{2}{r}{ Note: ${ }^{\text {a } ~ C V ~ a n d ~ C E ~ m e a n ~ c o n t i n g e n t ~ v a l u a t i o n ~ a n d ~ c h o i c e ~ e x p e r i m e n t, ~ r e s p e c t i v e l y . ~}$}
\end{tabular}

Saphores et al. [8] analyzed consumer preferences and additional WTP for 'greener' electronic devices by designing a CE. Ward et al. [9] investigated consumers' additional WTP for a refrigerator produced by a company that is a member of the Green Power Partnership using a CE method. Milovantseva [10] conducted a CV to look into the WTP for a green cell phone. Min et al. [11] examined the consumers' WTP a premium for eco-labeled 43-inch LED TV by applying CV.

\subsection{Method: CV Approach}

As addressed above, the primary purpose of this article was to obtain information on consumers' WTP price premium for a RE100 smartphone in South Korea. One complication in conducting the survey is the fact that the market of RE100 smartphones has not yet been formed in South Korea. In this case, revealed preference methods utilizing data obtained from the market cannot be applied. Therefore, a nonmarket good valuation method that can be applied to investigate consumers' preference for a good or service that cannot be evaluated in the market should be adopted here.

The CV approach can be applied to measure consumers' WTP to consume a good or service [10-12]. Similarly, consumers' WTP price premium for a RE100 smartphone can be elicited through the application of the $\mathrm{CV}$ method. The use of the $\mathrm{CV}$ technique is conceptually correct in the measurement of economic benefits [6,13-15]. The CV method directly asks respondents to determine their WTP contingent on a proposed situation. Arrow et al. [3] proposed several measures to ensure that a CV study is valid and accurate. For instance, a detailed and persuasive explanation of the goods of concern should be provided in the CV survey. The goods and the method of providing and paying for them should be meaningful to people. Well-trained and professional enumerators should be used $[11,16]$.

\subsection{Survey Instrument (Questionnaire)}

We prepared a survey questionnaire with the assistance of experts at a professional polling company and tested the pilot questionnaire with a focus group to see how much potential respondents understood the questions. The final version reflected the inputs of the focus group as well as the advice provided by the experts at the polling company who were assigned to organize the fieldwork. The results of a focus group interview administered to 100 individuals enabled us to modify and supplement the early version of the CV survey instrument. The finalized survey questionnaire comprises three sections. The first section presents an explanation of the aim and scope of the survey and warm-up questions about their perceptions related to the RE100 smartphone to the respondents. The interviewers also gave several well-illustrated visual cards to respondents. The second section deals with the collection of information about WTP in earnest, explaining the meaning and principle of additional payments and then asking their WTP. The third section relates to the collection of personal information about the respondents, and it included income, age, education, gender, and so on.

A Galaxy S9 price surcharge was chosen for the payment vehicle, because the Galaxy S9 was the latest release of the Samsung Electronics' Galaxy series at the time of the survey and a representative smartphone in South Korea. Some former studies used a surcharge of a product price as a payment vehicle [11,16]. a distribution for the WTP price premium values collected through open-ended questions in a pre-test of the focus group was created, and then the range and number of suggested 
bid amounts were determined using a trimmed distribution that cuts a percentage at each end of the WTP distribution. The main part of the survey questionnaire in this study is given in Appendix A.

\subsection{WTP Question}

A dichotomous choice (DC) question is widely used for deriving a WTP response. Generally, the most commonly used types of DC question methods are single-bounded, double-bounded, and one-and-one-half-bounded (OOHB) DC question methods. The first type is simple and convenient but not statistically efficient compared to the second method. Whereas the estimates resulting from the second type can gain statistical efficiency, the second type may generate inconsistency due to the correlation between the first and the second bids [17-19] and can cause a compliance issue [20].

The use of the OOHB DC question type offered by Cooper et al. [18] is able to resolve problems such as the inefficiency of the first method and the inconsistency of the second method. The merits of the OOHB DC format have promoted its application in a substantial number of previous studies [21-25]. Consequently, this article utilized the OOHB DC question method. Two bids, one of which is higher than the other, were used in the OOHB DC question. If a lower bid is presented to an interviewee first and the answer is "yes", a higher bid is additionally offered to the interviewee. If a lower bid is presented to an interviewee first and the answer is "no", no additional question is offered to the interviewee. When a higher bid is presented to an interviewee first and the answer is "no", a lower bid is additionally offered to the interviewee. If a higher bid is presented to an interviewee first and the answer is "yes", no additional question is offered to the interviewee.

\subsection{Spike Model}

The following explanation is based on a utility difference approach [26]. An interviewee will say "yes" to a suggested bid, $T$, if the following condition meets:

$$
V(Y, I-T ; D)+\lambda_{Y} \geq V(N, I ; D)+\lambda_{N}
$$

where $Y$ and $N$ indicate the states in which a RE100 smartphone is purchased and conventional non-RE100 smartphone is purchased, respectively, $V$ is an indirect utility function, $I$ is the household's income, $D$ is the household's sociodemographic characteristics, and the $\lambda \mathrm{s}$ are the error terms. The utility difference function takes the following form:

$$
\Delta V=V(Y, I-T ; D)-V(N, I ; D) \geq \lambda_{N}-\lambda_{Y}
$$

If $\Delta V$ is positive, the respondent may say "yes". Thus, the following relationship can be derived from:

$$
\operatorname{Pr}(\text { "yes" })=\operatorname{Pr}(W \geq T)=1-F_{W}(T)
$$

where $W$ and $F_{W}(\cdot)$ are the interviewee's WTP and the cumulative distribution function (CDF) of $W$.

There are $R$ respondents. $T$ presented to respondent $s$ is expressed as $T_{s}$ for $s=1, \ldots, R$. Let $T_{s}^{L}$ and $T_{s}^{H}$ be lower and higher bids. If $T_{s}^{L}$ is offered to the respondent first, "yes-yes", "yes-no", and "no" are the possible responses. When $T_{s}^{H}$ is provided to the respondent first, "yes", "no-yes", and "no-no" 
are the possible answers [23]. Thus, a total of six indicator variables can emerge from the OOHB DC question format. Hence, $E_{s}^{Y Y}, E_{s}^{Y N}, E_{s}^{N}, E_{s}^{Y}, E_{s}^{N Y}$, and $E_{s}^{N N}$ are introduced as follows [21-25]:

$$
\begin{aligned}
& E_{s}^{Y Y}=1(\text { sth interviewee's answer is "yes-yes") } \\
& E_{s}^{Y N}=1(\text { sth interviewee's answer is "yes-no") } \\
& E_{s}^{N}=1(\text { sth interviewee's answer is "no") } \\
& E_{s}^{Y}=1(\text { sth interviewee's answer is "yes") } \\
& E_{s}^{N Y}=1(\text { sth interviewee's answer is "no-yes") } \\
& E_{s}^{N N}=1(\text { sth interviewee's answer is "no-no") }
\end{aligned}
$$

where $1(\cdot)$ is an indicator function [21]. It has a value of one if the proposition in the parentheses is true and a value of zero otherwise.

An interviewee who responds "no-no" to $T_{s}^{H}$ or "no" to $T_{s}^{L}$ is given a follow-up question asking whether she/he has the intention to pay nothing [21]. If the response is "yes", $0<W_{s}<T_{s}^{L}$ comes into effect, and otherwise, $W_{s}=0$. To reflect these points, additional indicator variables are considered as follows [21,27]:

$$
\begin{aligned}
& E_{s}^{T Y}=1(\text { s th interviewee's answer to the additional question is "yes") } \\
& E_{s}^{T N}=1\left(\text { sth interviewee's answer to the additional question is " } \mathrm{no}^{\prime \prime}\right)
\end{aligned}
$$

Thus, the log-likelihood function derived for the OOHB DC spike model is $[7,21,27,28]$ :

$$
\begin{aligned}
\ln L= & \sum_{s=1}^{R}\left\{\left(E_{s}^{Y Y}+E_{s}^{Y}\right) \ln \left[1-F_{W}\left(T_{s}^{U} ; \phi_{0}, \phi_{1}\right)\right]\right. \\
& +\left(E_{s}^{Y N}+E_{s}^{N Y}\right) \ln \left[F_{W}\left(T_{s}^{U} ; \phi_{0}, \phi_{1}\right)-F_{W}\left(T_{s}^{L} ; \phi_{0}, \phi_{1}\right)\right] \\
& +E_{s}^{T Y}\left(E_{s}^{N}+E_{s}^{N N}\right) \ln \left[F_{W}\left(T_{s}^{L} ; \phi_{0}, \phi_{1}\right)-F_{W}\left(0 ; \phi_{0}, \phi_{1}\right)\right] \\
& \left.+E_{s}^{T N}\left(E_{s}^{N}+E_{s}^{N N}\right) \ln F_{W}\left(0 ; \phi_{0}, \phi_{1}\right)\right\}
\end{aligned}
$$

In the spike model, $F_{W}\left(T ; \phi_{0}, \phi_{1}\right)$ is assumed as:

$$
F_{W}\left(T ; \phi_{0}, \phi_{1}\right)= \begin{cases}{\left[1+\exp \left(\phi_{0}-\phi_{1} T\right)\right]^{-1}} & \text { if } T>0 \\ {\left[1+\exp \left(\phi_{0}\right)\right]^{-1}} & \text { if } T=0 \\ 0 & \text { if } T<0\end{cases}
$$

The probability of $W_{s}=0$ is usually called the spike, which corresponds to $\left[1+\exp \left(\varphi_{0}\right)\right]^{-1}$ in Equation (7) [28]. Since our main concern is to measure the mean WTP, we need to compute it from $F_{W}\left(T ; \varphi_{0}, \varphi_{1}\right)$. If a well-known formula for the mean calculated from a CDF is used, we obtain the mean WTP as $\left(1 / \varphi_{1}\right) \ln \left[1+\exp \left(\varphi_{0}\right)\right][21,26,27]$.

\section{Results}

\subsection{Data}

As mentioned above, a survey of 1000 interviewees was implemented to gather the data. a professional polling company managed the entire process of the nationwide survey in August 2018. For example, supervisors from the company trained interviewers and conducted stratified random sampling matching the characteristics of the population. Furthermore, following Arrow et al.'s [3] recommendation, the survey was implemented through person-to-person interviews. Participants who responded faithfully to the survey were given a gift in the price range of USD 3 to 5 .

One of the finally determined bid amounts was randomly presented to each respondent. The sets of lower and higher bids in KRW 1000 are the following: $(4,12),(8,16),(12,24),(16,32),(24,40)$, $(32,48)$, and $(40,60)$. In the course of the survey, USD 1 was approximately KRW 1113 . The distribution of responses to the bid amounts presented to the respondents is shown in Table 2. About $62.2 \%$ of 
all the respondents were found to have no intention of paying extra only 1 Korean won to purchase a RE100 smartphone. Therefore, it can be seen that applying the spike model is an appropriate strategy.

Table 2. Responses to willingness to pay questions.

\begin{tabular}{|c|c|c|c|c|c|c|c|c|c|c|}
\hline & & \multicolumn{4}{|c|}{ Higher Bid Is Given First (\%) ${ }^{b}$} & \multicolumn{4}{|c|}{ Lower Bid Is Given First (\%) ${ }^{b}$} & \multirow[b]{2}{*}{ Sample Size } \\
\hline \multicolumn{2}{|c|}{ Bid Amount ${ }^{a}$} & "yes-yes" & " "yes-no" & "no-yes" & "no-no" & "yes" & "no-yes" & "no-no-yes" & "no-no-no" & \\
\hline 4 & 12 & $12(8.4)$ & $14(9.8)$ & $6(4.2)$ & $40(28.0)$ & $20(14.0)$ & $7(4.9)$ & $4(2.8)$ & $40(28.0)$ & $143(100.0)$ \\
\hline 8 & 16 & $8(5.6)$ & $10(6.9)$ & $11(7.6)$ & $43(29.9)$ & $12(8.3)$ & $9(6.3)$ & $10(6.9)$ & $41(28.5)$ & $144(100.0)$ \\
\hline 12 & 24 & $14(9.8)$ & $8(5.6)$ & $11(7.7)$ & $38(26.6)$ & $8(5.6)$ & $13(9.1)$ & $9(6.3)$ & $42(29.4)$ & $143(100.0)$ \\
\hline 16 & 32 & $5(3.5)$ & $10(7.0)$ & $11(7.7)$ & $45(31.7)$ & $8(5.6)$ & $3(2.1)$ & $12(8.5)$ & $48(33.8)$ & $142(100.0)$ \\
\hline 24 & 40 & $6(4.2)$ & $4(2.8)$ & $13(9.2)$ & $48(33.8)$ & $10(7.0)$ & $3(2.1)$ & $4(2.8)$ & $54(38.0)$ & $142(100.0)$ \\
\hline 32 & 48 & $6(4.2)$ & $3(2.1)$ & $12(8.5)$ & $50(35.2)$ & $11(7.7)$ & $1(0.7)$ & $16(11.3)$ & $43(30.3)$ & $142(100.0)$ \\
\hline 40 & 60 & $7(4.9)$ & $9(6.3)$ & $9(6.3)$ & 47 (32.6) & $13(9.0)$ & $8(5.6)$ & $8(5.6)$ & $43(29.9)$ & $144(100.0)$ \\
\hline \multicolumn{2}{|c|}{ Totals } & $58(5.8)$ & $58(5.8)$ & $73(7.3)$ & $311(31.1)$ & $82(8.2)$ & $44(4.4)$ & $63(6.3)$ & $311(31.1)$ & $1000(100.0)$ \\
\hline
\end{tabular}

Notes: ${ }^{a}$ The unit is 1000 Korean won. In the course of the survey, USD 1 was approximately KRW 1113.

$\mathrm{b}$ The percentage of the responses is given in parentheses next to the number of respondents.

The no-response of $62.2 \%$ can be divided into true zero and protest zero. In this study, true zero and protest zero were $60 \%$ and $40 \%$, respectively. The former means that a respondent is not willing to pay because they believe that a RE100 smartphone does not contribute at all to their benefit. The latter means rejection of the CV survey itself, generally for the following reasons: The question is too difficult to understand; the government is not confident in pursuing the proposed plan or project; the government is already spending too much money on this field; the person who caused the problem, not me, has to pay; I do not like this type of question at all; and this is not my concern. Therefore, it is difficult to view the protest zero as a reasonable response, and it is desirable to exclude it from the analysis. However, there may be a case where the benefit is largely estimated due to the elimination of protest zero. For this reason, in this study, both the true zero and the protest zero were included in the no-response for conservative analysis.

\subsection{Estimation Results}

Table 3 reports the estimation results of the model given in Equation (6) using the TSP 5.1 software. All the parameter estimates are statistically significant at the $1 \%$ level. The estimated equation is significant judging from the Wald statistic. In addition, the sign of the coefficient estimates meets the prior expectations. The consumers' WTP price premium for a RE100 smartphone is KRW 11,699 (USD 10.5), which is also statistically significant.

Table 3. Estimation results of the spike model.

\begin{tabular}{lc}
\hline Variables & Coefficient Estimates ( $t$-Values) \\
\hline Constant & $-0.524(-8.11)^{\#}$ \\
Bid amount ${ }^{\#}$ & $-0.040(-16.59)^{\#}$ \\
Spike & $0.628(41.62)^{\#}$ \\
Mean WTP & KRW 11,699(USD 10.5) \\
$\quad t$-value & $14.14^{\#}$ \\
$95 \%$ CI $^{\text {a }}$ & KRW 10,242 to 13,490 (USD 9.2 to \\
& $12.1)$ \\
$99 \%$ CI $^{\text {a }}$ & KRW 9825 to 14,098 (USD 8.8 to \\
Sample size & $12.7)$ \\
Log-likelihood $_{\text {Wald statistic }(p \text {-value) }}{ }^{\mathrm{b}}$ & 1000 \\
\hline
\end{tabular}

Notes: ${ }^{a}$ CI means confidence interval and is calculated using the method given in Krinsky and Robb [29]. ${ }^{b}$ The null hypothesis is that all the parameters are jointly $0 .{ }^{\#}$ denotes statistical significance at the $1 \%$ level.

It would be preferable to provide a confidence interval (CI) rather than a point estimate to reflect explicitly the uncertainty associated with the mean WTP estimation process. Applying the 
method reported by Krinsky and Robb [29] to the estimation results for both parameters, $\varphi_{0}$ and $\varphi_{1}$, produces the CI for the mean WTP price premium. Table 3 contains the $95 \%$ and $99 \%$ CIs.

As the next step, it is necessary to deal with a model including covariates that can address the effect of the covariates on the probability that the respondents will answer "yes" to the proposed bid amount. Moreover, the model can be used for deciding whether the results of applying the CV method involving the survey will ensure internal consistency or theoretical validity. For this purpose, this study employed four covariates, which are explained in Table 4 . Table 5 shows the results of the model estimation.

Table 4. Description of the variables in the model.

\begin{tabular}{llcc}
\hline \multicolumn{1}{c}{ Variables } & \multicolumn{1}{c}{ Definitions } & Mean & Standard Deviation \\
\hline Education & Education level of the respondent in years & 14.09 & 2.23 \\
Income & $\begin{array}{l}\text { Respondent's households' income per } \\
\text { month (unit: million Korean won) }\end{array}$ & 4.91 & 2.14 \\
Head & Whether the respondent is the head of & 0.53 & 0.50 \\
Age & household (1 = head; 0 otherwise) & 47.78 & 9.20 \\
\hline
\end{tabular}

Table 5. Estimation results of the spike model with covariates.

\begin{tabular}{ccc}
\hline Variables $^{\text {a }}$ & Coefficient Estimates & $t$-Values \\
\hline Constant & -1.997 & $-2.78^{\#}$ \\
Education & 0.146 & $4.11^{\#}$ \\
Income & 0.069 & $2.16^{\#}$ \\
Head & -0.105 & -0.79 \\
Age & -0.019 & $-2.31^{\#}$ \\
Bid amount & -0.041 & $-16.67^{\#}$ \\
Number of observations & \multicolumn{3}{|}{1000} \\
Log-likelihood $_{\text {Wald statistic ( } p \text {-value) }}{ }^{\mathrm{b}}$ & \multicolumn{3}{c}{$196.38(0.000)$} \\
\hline
\end{tabular}

Notes: ${ }^{a}$ Table 4 defines the variables. ${ }^{\mathrm{b}}$ The null hypothesis is that all the parameters are jointly zero. ${ }^{\#}$ denotes statistical meaningfulness at the $1 \%$ level.

Of the four covariates, the estimated coefficients for the three covariates are statistically meaningful at the $1 \%$ level. The sign of an estimated coefficient for a particular variable is positive (negative), which means that the value of that variable has a positive (negative) relationship with the probability of responding "yes" to the proposed bid amount. For instance, the respondent's education level affects their acceptance of the bid price. The respondent's education level is positively correlated with the likelihood of reporting "yes" to a given bid. The respondents who were older were more reluctant to say "yes" to an offered bid than others. In addition, rich respondents had a greater tendency to answer "yes" to a suggested bid than others.

\subsection{Discussion of the Results}

To investigate consumers' preferences for a RE100 smartphone, the mean WTP price premium for the RE100 smartphone over a Galaxy S9 was computed. As noted earlier, in this study, skilled interviewers belonging to a professional polling company conducted the CV surveys with 1000 people nationwide. The authors therefore believe that this sample is well balanced and representative. To confirm this, the household's monthly income, the ratio of female respondents, and the size of the household are checked here. The sample average for the variables were KRW 4.91 million, $48.4 \%$, and 3.27 persons. The population average for those were KRW 4.61 million, 49.9\%, 3.07 persons when the survey was conducted [30]. The lack of significant gaps between the two values for each variable confirms that our sample has strong representativeness.

The consumers' mean WTP price premium for a RE100 smartphone is KRW 11,699 (USD 10.5). This value amounts to $1.6 \%$ of the price of the conventional one, Galaxy S9 (KRW 750,000 or USD 
673.9). The $95 \%$ and $99 \%$ confidence intervals for the point estimate of WTP price premium were KRW 10,242 to 13,490 (USD 9.2 to 12.1) and KRW 9825 to 14,098 (USD 8.8 to 12.7), and these values account for $1.4 \%$ to $1.8 \%$ and $1.3 \%$ to $1.9 \%$, respectively, of the price of a conventional non-RE100 smartphone.

In Samsung Electronics, electric charges account for $1 \%$ of the total production costs [31]. As of 2017, the average charge of industrial electricity was KRW 107/kWh (USD 0.10/kWh), and that of electricity produced from RE was KRW 211/kWh (USD 0.18/kWh). Therefore, if Samsung Electronics uses electricity produced from RE instead of industrial electricity that is mostly produced from fossil fuels and nuclear power, it can be predicted that the electricity charges of the manufacturing cost will rise by $0.97 \%$. Comparing this expected increase of cost with the average WTP price premium, consumers indicate that they are willing to pay more than the extra cost of manufacturing.

It is clear that the respondents are willing to accept some economic strain to purchase a RE100 smartphone. Thus, these implications can provide fundamental information justifying the company investment to use RE instead of energy produced from fossil fuel. Corporate efforts to use $100 \%$ RE are not only socially responsible for global climate change but are also meeting consumer needs. This study analyzed consumers' WTP price premium for a RE100 smartphone from Samsung Electronics, which is the second most power-intensive company in South Korea. Samsung Electronics announced in June 2018 that it would participate in RE100. The change in Samsung Electronics is expected to have a domino effect on many other companies.

\section{Conclusions}

Adequately responding to climate change issues is an important indicator of a company's competitiveness. Many companies have declared joining the RE100 campaign. As many investments are needed to use RE instead of the energy produced from fossil fuels, information on the consumers' preference for a RE100 commodity is important. This article intended to assess consumers' WTP price premium for the RE100 commodity using the specific case study of a smartphone, which is the most common type of electronic devices in South Korea.

It seems that our work is meaningful from the industry, policy, and research perspectives. From an industry perspective, the work reported the potential implications of RE100 commodities using the specific case of smartphones. In South Korea, the market of RE100 smartphones has not yet been formed. Generally, if the commodity is not traded in the market, it is quite difficult to assess the economic benefits. However, the results of this study can be used to estimate the economic benefits of a RE100 commodity. In particular, the result can be adopted by companies as a basis for the investment needed to use RE.

From a policy perspective, with more and more global companies joining the RE100, creating a policy environment that facilitates the production and purchasing of RE is also linked to national industrial competitiveness. The South Korean government aims to increase the proportion of RE to $20 \%$ by 2030 . In addition to expanding the proportion of RE, the government should create policies such as a green electricity tariff system and power purchase agreement for domestic companies to use the produced RE. We can see that South Korean consumers support such policy changes.

From a research perspective, this study effectively used CV to estimate consumers' price premium for RE100 products. To the extent of the authors' knowledge, there are many studies that have found WTP for expanding RE, but few have obtained a price premium for RE100 products. In this respect, this study contributes not only to CV literature but also to RE100 literature. In the future, if the framework of this study is expanded to other RE100 products, and if there are more studies in other countries, we can compare them with each other and derive implications.

The authors think that the contents of the study can be extended in future studies in several ways. First, we need to examine whether respondents who value sustainable development have a greater WTP. It will be important to understand the extent to which interest in sustainable development is related to RE100 purchases. Second, it would also be meaningful to confirm whether respondents want to pay for RE when they buy smartphones. Third, this study only compared the RE100 smartphone with 
the conventional non-RE100 one, considering whether it was produced using $100 \% \mathrm{RE}$, and assumed that all other conditions are the same. However, further studies, such as whether the respondents prefer lower prices or better features among RE100 smartphones, will also be meaningful for accurate forecasting of consumers' preferences.

Author Contributions: This paper was created by all authors. J.-H.K. prepared a questionnaire, supervised the CV survey, and performed a statistical analysis with collected data. H.-J.K. wrote most of the paper while collecting the data. S.-H.Y. presented the direction of writing the paper, provided the key ideas for this study, and polished an initial version of the paper.

Funding: This work was supported by the Korea Institute of Energy Technology Evaluation and Planning (KETEP) and the Ministry of Trade, Industry \& Energy (MOTIE) of the Republic of Korea (No. 20184030202230).

Conflicts of Interest: The authors declare no conflict of interest.

\section{Appendix A Main Part of the Survey Questionnaire}

Part 1. Questions about willingness to pay price premium for smartphone produced using renewable energy

Type A. Q1. Are you willing to pay a price premium of 4000 Korean won (lower bid amount) to get a smartphone produced using $100 \%$ renewable energy?

a. Yes-go to Type A. Q2.

b. No-go to Q3.

Type A. Q2. Are you willing to pay a price premium of 12,000 Korean won (upper bid amount) to get a smartphone produced using $100 \%$ renewable energy?

a. Yes-Finish this survey

b. No-Finish this survey

Type B. Q1. Are you willing to pay a price premium of 12,000 Korean won (upper bid amount) to get a smartphone produced using $100 \%$ renewable energy?

a. Yes-Finish this survey

b. No-go to Type B. Q2.

Type B. Q2. Are you willing to pay a price premium of 4000 Korean won (lower bid amount) to get a smartphone produced using $100 \%$ renewable energy?

a. Yes-Finish this survey

b. No-go to Q3.

Q3. Then, are you not willing to pay a price premium of anything to get a smartphone produced using $100 \%$ renewable energy?

a. Yes, I am willing to pay price premium something less than 4000 Korean won.

b. No, I am not willing to pay anything. In other words, my willingness to pay price premium is zero.

\section{Part 2. Questions about socio-economic characteristics}

The respondents were asked to respond to their socioeconomic characteristics, such as the gender of the individual, the number of family members, the level of education, and the monthly income (before tax deduction). Questions about the number of family and income were open-ended questions, and the question about the level of education was as follows:

Q1. Please check with $\sqrt{ }$ your education level in years.

\begin{tabular}{c|c|c|c|c|c|c}
\hline Education Level & Uneducated & Elementary School & Middle School & High School & University & Graduate School \\
\hline $\begin{array}{c}\text { Education level } \\
\text { in years }\end{array}$ & 0 & 123456 & 789 & 101112 & 13141516 & 17181920 \\
\hline
\end{tabular}




\section{References}

1. Menegaki, A.N. The Economics and Econometrics of the Energy-Growth Nexus; Academic Press: Cambridge, MA, USA, 2018.

2. Samsung. Sustainability Report (in Korean). 2018. Available online: https://news.samsung.com (accessed on 15 December 2018).

3. Arrow, K.; Solow, R.; Portney, P.R.; Leamer, E.E.; Radner, R.; Schuman, H. Report of the NOAA panel on contingent valuation. Fed. Regist. 1993, 58, 4601-4614.

4. Fisher, A. The conceptual underpinnings of the contingent valuation method. In The Contingent Valuation of Environmental Resources; Bjornstad, D.J., Kahn, J.R., Eds.; Edward Elgar: Cheltenham, UK, 1996; pp. $19-37$.

5. Vehkatachalam, L. The contingent valuation method: a review. Environ. Impact. Assess. Rev. 2004, 24, 89-124. [CrossRef]

6. Lim, S.-Y.; Kim, H.-J.; Yoo, S.-H. South Korean household's willingness to pay for replacing coal with natural gas? a view from $\mathrm{CO}_{2}$ emissions reduction. Energies 2017, 10, 2031. [CrossRef]

7. Yoo, S.-H.; Kwak, S.-Y. Willingness to pay for green electricity in Korea: a contingent valuation study. Energy Policy 2009, 37, 5408-5416. [CrossRef]

8. Saphores, J.D.M.; Nixon, H.; Ogunseitan, O.A.; Shapiro, A.A. California households' willingness to pay for 'green' electronics. J. Environ. Plan. Manag. 2007, 50, 113-133. [CrossRef]

9. Ward, D.O.; Clark, C.D.; Jensen, K.L.; Yen, S.T. Consumer willingness to pay for appliances produced by Green Power Partners. Energy Econ. 2011, 33, 1095-1102. [CrossRef]

10. Milovantseva, N. Are American households willing to pay a premium for greening consumption of information and communication technologies? J. Clean. Prod. 2016, 127, 282-288. [CrossRef]

11. Min, S.-H.; Lim, S.-Y.; Yoo, S.-H. Consumers' willingness to pay a premium for eco-labeled LED TVs in Korea: a contingent valuation study. Sustainability 2017, 9, 814.

12. Brent, R.J. Applied Cost-Benefit Analysis, 2nd ed.; Edward Elgar: Cheltenham, UK, 2006.

13. Mitchell, R.C.; Carson, R.T. Using Surveys to Value Public Goods: The Contingent Valuation Method; RFF Press: New York, NY, USA, 1989.

14. Just, R.E.; Hueth, D.L.; Schmitz, A. The Welfare Economics of Public Policy: a Practical Approach to Project and Policy Evaluation; Edward Elgar: Cheltenham, UK, 2004.

15. Carson, R.T.; Hanemann, W.M. Contingent valuation. In Handbook of Environmental Economics: Valuing Environmental Changes; Mäler, K.G., Vincent, J.R., Eds.; Elsevier: Amsterdam, The Netherlands, 2005; Volume 2, pp. 821-936.

16. Kim, J.-H.; Kim, H.-J.; Yoo, S.-H. Consumers' willingness to pay for net-zero energy apartment in South Korea. Sustainability 2018, 10, 1564. [CrossRef]

17. Bateman, I.J.; Langford, L.H.; Jones, P.; Kerr, G.N. Bound and path effects in double and triple bounded dichotomous choice contingent valuation. Res. Energy Econ. 2001, 23, 191-213. [CrossRef]

18. Cooper, J.C.; Hanemann, M.; Signorello, G. One and one-half bound dichotomous choice contingent valuation. Rev. Econ. Stat. 2002, 84, 742-750. [CrossRef]

19. McFadden, D. Contingent valuation and social choice. Am. J. Agric Econ. 1994, 76, 689-708. [CrossRef]

20. Cameron, T.A.; Quiggin, J. Estimation using contingent valuation data from a "dichotomous choice with follow-up" questionnaire. J. Environ. Econ. Manag. 1994, 27, 218-234. [CrossRef]

21. Jang, J.; Lee, J.; Yoo, S.H. The public's willingness to pay for securing a reliable natural gas supply in Korea. Energy Policy 2014, 69, 3-13. [CrossRef]

22. Ponce, R.D.; Vásquez, F.; Stehr, A.; Debels, P.; Orihuela, C. Estimating the economic value of landscape losses due to flooding by hydropower plants in the Chilean Patagonia. Water Res. Manag. 2011, 25, 2449-2466. [CrossRef]

23. Park, S.-Y.; Lim, S.-Y.; Yoo, S.-H. Public willingness to pay a premium for uni-material beverage container in Korea: a contingent valuation study. Water Environ. J. 2018, 32, 229-234. [CrossRef]

24. Kim, J.; Lim, S.Y.; Yoo, S.H. Public willingness to pay for restoring destroyed tidal flats and utilizing them as ecological resources in Korea. Ocean. Coast. Manag. 2017, 142, 143-149. [CrossRef]

25. Delmond, A.R.; McCluskey, J.J.; Yormirzoev, M.; Rogova, M.A. Russian consumer willingness to pay for genetically modified food. Food Policy 2018, 78, 91-100. [CrossRef] 
26. Hanemann, W.M. Welfare evaluations in contingent valuation experiments with discrete responses. Am. J. Agric. Econ. 1984, 66, 332-341. [CrossRef]

27. Yoo, S.-H.; Kwak, S.-J. Using a spike model to deal with zero response data from double bounded dichotomous contingent valuation survey. Appl. Econ. Lett. 2002, 9, 929-932. [CrossRef]

28. Kriström, B. Spike models in contingent valuation. Am. J. Agric. Econ. 1997, 79, 1013-1023. [CrossRef]

29. Krinsky, I.; Robb, A.L. On approximating the statistical properties of elasticities. Rev. Econ. Stat. 1986, 68, 715-719. [CrossRef]

30. Statistics Korea. Korea Statistical Information Service. Available online: http://kosis.kr (accessed on 25 February 2019). (In Korean)

31. SBS News. Even Though You Can Lower the Electricity Bill for the Heat Wave This Year the Problem is that the Electricity Bill for the Industry is Used (in Korean). 2018. Available online: http:/ / news.sbs.co.kr (accessed on 15 December 2018).

(C) 2019 by the authors. Licensee MDPI, Basel, Switzerland. This article is an open access article distributed under the terms and conditions of the Creative Commons Attribution (CC BY) license (http://creativecommons.org/licenses/by/4.0/). 